\title{
Microstructure, phase composition and oxidation behavior of porous Ti-Si-Mo intermetallic compounds fabricated by reactive synthesis
}

https://doi.org/10.1515/htmp-2020-0022

Received Apr 11, 2019; accepted Apr 27, 2019

\begin{abstract}
Porous Ti-Si-Mo intermetallic compounds were fabricated by reactive synthesis using $\mathrm{C}_{7} \mathrm{H}_{10} \mathrm{~N}_{2} \mathrm{O}_{2} \mathrm{~S}$ as a foaming agent. The effects of Mo content on the microstructure, phase composition and oxidation behavior were investigated. The results show that the porosity and the fractal dimension decreases and then increases as the Mo content increases. It is found that the pore size is mainly distributed in less than $1 \mu \mathrm{m}$. The phase compositions mainly consist of $\mathrm{TiSi}, \mathrm{Ti}_{5} \mathrm{Si}_{4}, \mathrm{Mo}_{5} \mathrm{Si}_{3}$ and $\mathrm{TiO}$, and the $\mathrm{Ti}_{5} \mathrm{Si}_{3}$ phase is detected at Mo content of $16 \mathrm{wt} . \%$ in particular. In addition, the mass gain of the oxidized samples gradually decreases as the Mo content increases. It is concluded that the oxidation resistance at high-temperature generally decreases as the fractal dimension increases. It is suggested that porous Ti-Si-Mo intermetallic compounds have potential applications in sound absorption and heat dissipation at high-temperature.
\end{abstract}

Keywords: porous Ti-Si-Mo intermetallic compounds; reactive synthesis; microstructure; phase composition; oxidation resistance

\section{Introduction}

Porous materials with open pores possess many attractive properties such as low weight, high permeability, high thermal conductivity and high specific surface area and have wide applications in sound absorption, heat dissipation, filtration, separation and catalyst support because of the capillary structure of the open and small

\footnotetext{
*Corresponding Author: Jinming Ru: Institute of Advanced Man-

*Corresponding Author: Jinming Ru: Institute of Advanced Man-
ufacturing and Modern Equipment Technology, Jiangsu University, Zhenjiang, 212013, China; Email: jmru@ujs.edu.cn

Ya Wang, Yuemei Wang, Xiaojing Xu: Institute of Advanced Manufacturing and Modern Equipment Technology, Jiangsu University, Zhenjiang, 212013, China
} ๑ Open Access. @ 2020 J. Ru et al., published by De Gruyter. (cc) BY License pores acting as fluid channels [1-3]. However, the applications of porous materials are relatively limited in adverse environments, such as porous ceramics with brittleness and poor weldability, porous metals with poor hightemperature oxidation resistance and porous polymers with poor aging resistance and high-temperature resistance [4-6]. Carbon-carbon composites, superalloys and intermetallic compounds are currently widely applied in the high-temperature environment. Carbon-carbon composites have restricted applications because of their poor oxidation resistance [7]. The extreme working temperature of superalloys such as nickel-based alloys is approximately $1523 \mathrm{~K}$. By comparison, porous intermetallic compounds show advantages of excellent oxidation resistance and high working temperature [8]. Aluminides and metal silicides are typical intermetallic compounds and have been extensively investigated and applied. Al-based intermetallic compounds have low working temperatures of $1173 \sim 1373 \mathrm{~K}$ to be used as high-temperature structural materials because of their lower melting point [9]. However, refractory metal silicides are widely used as hightemperature structural materials due to their excellent performance at high-temperature. Ti-Si based intermetallic compounds have lower density and Mo-Si based intermetallic compounds have improved high-temperature oxidation resistance in refractory metal silicides [10, 11]. Moreover, the addition of Mo could improve the mechanical strength and room temperature plasticity of Ti-Si based intermetallic compounds [12]. Burk et al. [13] synthesized the intermetallic compound of Mo-37Si-40Ti (at.\%) in order to obtain nearly single-phase $(\mathrm{Mo}, \mathrm{Ti})_{5} \mathrm{Si}_{3}$. The intermetallic compound Mo-37Si-40Ti possessed superior hightemperature oxidation resistance compared to both singlephase $\mathrm{Mo}_{5} \mathrm{Si}_{3}$ and single-phase $\mathrm{Ti}_{5} \mathrm{Si}_{3}$ due to the formation of a protective $\mathrm{SiO}_{2}-\mathrm{TiO}_{2}$ duplex scale. It's important to consider the advantages of two kinds of metal silicides in the integration and development of new porous Ti-SiMo intermetallic compound materials. Yang et al. [14] established the isothermal sections of the Mo-Si-Ti system to describe the solid-state phase equilibrium. The thermody- 


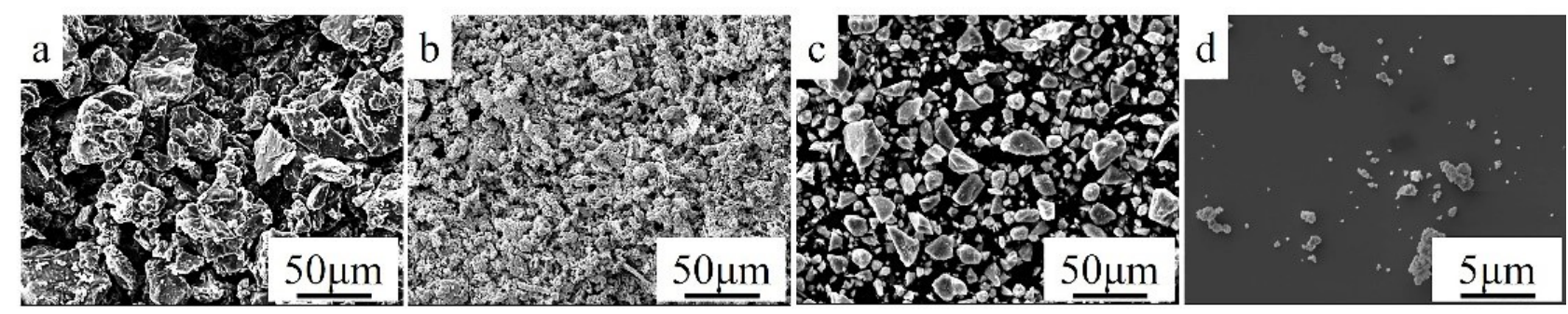

Figure 1: The SEM images of Ti-Si-Mo powder mixtures before and after ball milling: (a) Ti powders before ball milling; (b) Mo powders before ball milling; (c) Si powders before ball milling; (d) Ti-Si-Mo powders after ball milling

namic modeling satisfactorily explained the available experimental observation, and two invariant reactions close to the metal-rich region of the Mo-Si-Ti system, which are important in developing high-temperature structural materials, were calculated from this thermodynamic modeling. Porous Ti-Si-Mo intermetallic compounds have the potential for applications in high-temperature oxidative environments.

Porous intermetallic compounds can be prepared by powder metallurgy techniques, such as hot isostatic pressing, reactive synthesis, combustion synthesis, mechanical alloying and thermal or plasma spraying. Reactive synthesis and combustion synthesis have been applied to prepare various intermetallic compound materials. Feng et al. [15] produced porous titanium silicides with an open porosity ranging from $17 \%$ to $55 \%$ by combustion synthesis from elemental powders of $\mathrm{Ti}$ to $\mathrm{Si}$ in varying molar ratios. It was concluded that the formation of pores resulting from the melting and flow of reactants or products with low melting points during the combustion process is an especially rapid synthesis process. Gao et al. [16] prepared porous Fe-Al intermetallics with an open porosity of approximately $40 \%$ by the reactive synthesis of $\mathrm{Fe}$ and $\mathrm{Al}$ elemental powders. The liquid $\mathrm{Al}$ reaction and the phase transformation during sintering partly resulted in forming pores. He et al. [17] fabricated Ti-Al micrometer/nanometersized porous alloys with adjustable pore sizes ranging from the micrometer to nanometer scale via the Kirkendall effect, and the open porosity ranged from $40 \%$ to $60 \%$. Pore formation resulted from the Kirkendall effect due to the different diffusion rates of different elements [18]. It was concluded that the low diffusion rate of Mo atoms in the Ti-Mo diffusion couples results in the formation of pores [19]. Porous intermetallic compounds fabricated by reactive synthesis and the Kirkendall effect possess higher porosity and a wide pore size distribution range. Hence, the reactive synthesis and Kirkendall effect have advantages for the production of porous intermetallic compounds.
In this paper, porous Ti-Si-Mo intermetallic compounds are produced via reactive synthesis using $\mathrm{C}_{7} \mathrm{H}_{10} \mathrm{~N}_{2} \mathrm{O}_{2} \mathrm{~S}$ as a foaming agent. This study will focus on the porous structure and oxidation behavior. The effects of the Mo content on the microstructure and hightemperature oxidation behavior were investigated.

\section{Experimental}

\subsection{Material Preparation}

The typical processing of porous Ti-Si-Mo intermetallic compounds fabricated by reactive synthesis involved four steps: ball milling, pressing, foaming and sintering. After several attempts, titanium (200-300 mesh, 99.0\% purity), silicon (200 mesh, 99.9\% purity) and molybdenum (200 mesh, 99.0\% purity) elemental powders were mixed in four different mass ratios: (a) Ti-8Si-12Mo, (b) Ti-8Si-14Mo, (c) Ti-8Si-16Mo and (d) Ti-8Si-18Mo respectively, considering the forming performance during the sintering procedure and various performances such as fracture toughness of the sintered samples. The powder mixtures were highenergy ball milled in a planetary ball mill in the air for $48 \mathrm{~h}$ using agate balls without milling media. The ball-topowder weight ratio was 10:1 and the speed of the planetary ball mill was $500 \mathrm{r} / \mathrm{min}$. The SEM images of Ti-Si-Mo powder mixtures before and after ball milling, as shown in Figure 1. It is can be seen that Ti-Mo-Si powders with particle size in the range of submicron and micron scales could be obtained by ball milling with Ti powders with particle size of $50 \mu \mathrm{m}$, Mo powders with particle size of $5 \mu \mathrm{m}$ and Si powders with particle size in the range of $5 \mu \mathrm{m}-$ $25 \mu \mathrm{m}$ as raw materials. After adding $2 \mathrm{wt} . \% \mathrm{C}_{7} \mathrm{H}_{10} \mathrm{~N}_{2} \mathrm{O}_{2} \mathrm{~S}$ ( $>98.0 \%$ purity) with particle size of approximately $75 \mu \mathrm{m}$ into the powder mixtures as a foaming agent, the powder mixtures were ball milled in the planetary ball mill for 30 $\mathrm{min}$ at the speed of $200 \mathrm{r} / \mathrm{min}$ to be more uniform. The powder mixtures were then cold-pressed into cylindrical com- 
Table 1: Microstructure and oxidation behavior of sintered samples with different Mo contents

\begin{tabular}{cccccc}
\hline Sample & $\begin{array}{c}\text { Porosity } \\
(\%)\end{array}$ & $\begin{array}{c}\text { Surface area } \\
\left(\mathrm{m}^{2} \cdot \mathrm{g}^{-1}\right)\end{array}$ & Fractal dimension & $\begin{array}{c}\text { Average pore } \\
\text { diameters }(\mathrm{nm})\end{array}$ & $\begin{array}{c}\text { Mass gain after oxidation for } \\
100 \mathrm{~h}\left(\mathrm{~g} \cdot \mathrm{m}^{-2}\right)\end{array}$ \\
\hline $\mathrm{a}$ & 44.18 & 2.728 & 2.891 & 287.1 & 0.136 \\
$\mathrm{~b}$ & 41.94 & 2.862 & 2.887 & 246.5 & 0.111 \\
$\mathrm{c}$ & 40.58 & 2.622 & 2.880 & 253.1 & 0.106 \\
$\mathrm{~d}$ & 42.54 & 2.676 & 2.886 & 268.3 & 0.092 \\
\hline
\end{tabular}

pacts with the size of $\Phi 30 \times 3 \mathrm{~mm}$ under 50 100 MPa pressure. Before sintering, the compacts were dried at $383 \mathrm{~K}$ in vacuum of $10^{-1} \mathrm{~Pa}$ for $2 \mathrm{~h}$ to remove $\mathrm{C}_{7} \mathrm{H}_{10} \mathrm{~N}_{2} \mathrm{O}_{2} \mathrm{~S}$. Finally, the green compacts were sintered at $1123 \mathrm{~K}$ for $2 \mathrm{~h}$ and then at $1473 \mathrm{~K}$ for $4 \mathrm{~h}$ under a vacuum of $10^{-1} \mathrm{~Pa}$ with a heating rate of $4 \mathrm{~K} / \mathrm{min}$ throughout the sintering procedure.

\subsection{Characterization}

The microstructure of the sintered and oxidized samples was observed using a scanning electron microscope (SEM, JSM-IT300) operated at $10.0 \mathrm{kV}$. A Micromeritics' AutoPore IV 9510 automatic mercury porosimeter was employed to characterize the porosity and pore size distribution. The phase composition of the sintered and oxidized samples was detected by a D8-Advance X-ray diffraction (XRD) with a scanning angle of $20^{\circ} \sim 90^{\circ}$ and a scanning speed of $5^{\circ} / \mathrm{min}$. High-temperature oxidation behavior of the samples was tested in a Muffle furnace at $1473 \mathrm{~K}$ for $100 \mathrm{~h}$. The mass gain of the oxidized samples was measured using an electronic analytical balance every $20 \mathrm{~h}$. The fractal dimension was calculated by Eq. (1) [20].

$$
D=3-\ln \epsilon / \ln \left(r_{\min } / r_{\max }\right)
$$

where $\epsilon$ is the porosity and, $\mathbf{r}_{\min }$ and $\mathbf{r}_{\max }$ are the smallest and largest pore radius, respectively.

\section{Result and discussions}

Table 1 summarizes the pore structure and oxidation behavior of samples with different Mo contents. The open porosity of the sintered samples decreases from $44.18 \%$ to $40.58 \%$ and then increases to $42.54 \%$ and the fractal dimension decreases from 2.891 to 2.880 and then increases to 2.886 as the Mo content increases from $12 \mathrm{wt} . \%$ to 18 wt.\%. The bcc Ti and bcc Mo are completely soluble above $882^{\circ} \mathrm{C}$. However, the interdiffusion coefficients of the Ti-Mo binary system decreased with Mo content increased [21]. Hence, the porosity of porous Ti-Si-Mo intermetallic com- pounds decreased with Mo content increased. Meanwhile, the content of Mo oxides in Ti-Si-Mo powder mixtures increased with Mo content increased during ball milling. Volatilization of Mo oxides led to the increase of porosity when the Mo content is $18 \mathrm{wt} . \%$. The pore size is mainly distributed in less than $1 \mu \mathrm{m}$ and the average pore diameter of the sintered samples is very close, ranging from merely $246.5 \mathrm{~nm}$ to $287.1 \mathrm{~nm}$ according to the results. It was concluded that the pore sizes are larger while the porosity is higher. The surface area which is needed to obtain reliable oxidation behavior has little difference and ranges from $2.622 \mathrm{~m}^{2} \cdot \mathrm{g}^{-1}$ to $2.862 \mathrm{~m}^{2} \cdot \mathrm{g}^{-1}$. The mass gain gradually decreases from $0.136 \mathrm{~g} \cdot \mathrm{m}^{-2}$ to $0.092 \mathrm{~g} \cdot \mathrm{m}^{-2}$ after being oxidized for $100 \mathrm{~h}$ as the content of Mo increases from 12 wt. $\%$ to $18 \mathrm{wt} . \%$. It is found that the mass gain of porous Ti-Si-Mo intermetallic compounds decreased with porosity decreased from $44.18 \%$ to $40.58 \%$. Lower porosity reduced the oxygen intake and resulted in the decrease of mass gain. Meanwhile, the stability of the oxides in porous Ti$\mathrm{Si}-\mathrm{Mo}$ intermetallic compounds follows the trend of $\mathrm{TiO}_{2}$ $>\mathrm{SiO}_{2}>\mathrm{MoO}_{3}>\mathrm{MoO}_{2}$ according to standard free energy $\left(\Delta \mathrm{G}^{\circ}\right)$. More $\mathrm{MoO}_{3}$ volatilized during the oxidation process and the mass gain of porous Ti-8Si-18Mo intermetallic compounds continued to decrease. Hence, the mass gain of porous Ti-8Si-18Mo was only $0.092 \mathrm{~g} \cdot \mathrm{m}^{-2}$ for more Mo oxides volatilized during the oxidation process.

\subsection{Microstructure and Pore Size Distribution}

The internal pore structure and pore size distribution of porous Ti-Si-Mo intermetallic compounds fabricated by reactive synthesis are shown in Figure 2. The samples consisting of a few large pores and many small pores have excellent complexity and connectivity. The distribution of pores less than $1 \mu \mathrm{m}$ is magnified, as shown in Figure 2a"d". It is can be seen that the pore sizes of all samples are mainly distributed from $200 \mathrm{~nm}$ to $400 \mathrm{~nm}$. A small number of pores have a size of approximately $90 \mu \mathrm{m}$ due to the decomposition of $\mathrm{C}_{7} \mathrm{H}_{10} \mathrm{~N}_{2} \mathrm{O}_{2} \mathrm{~S}$ with particles of approxi- 

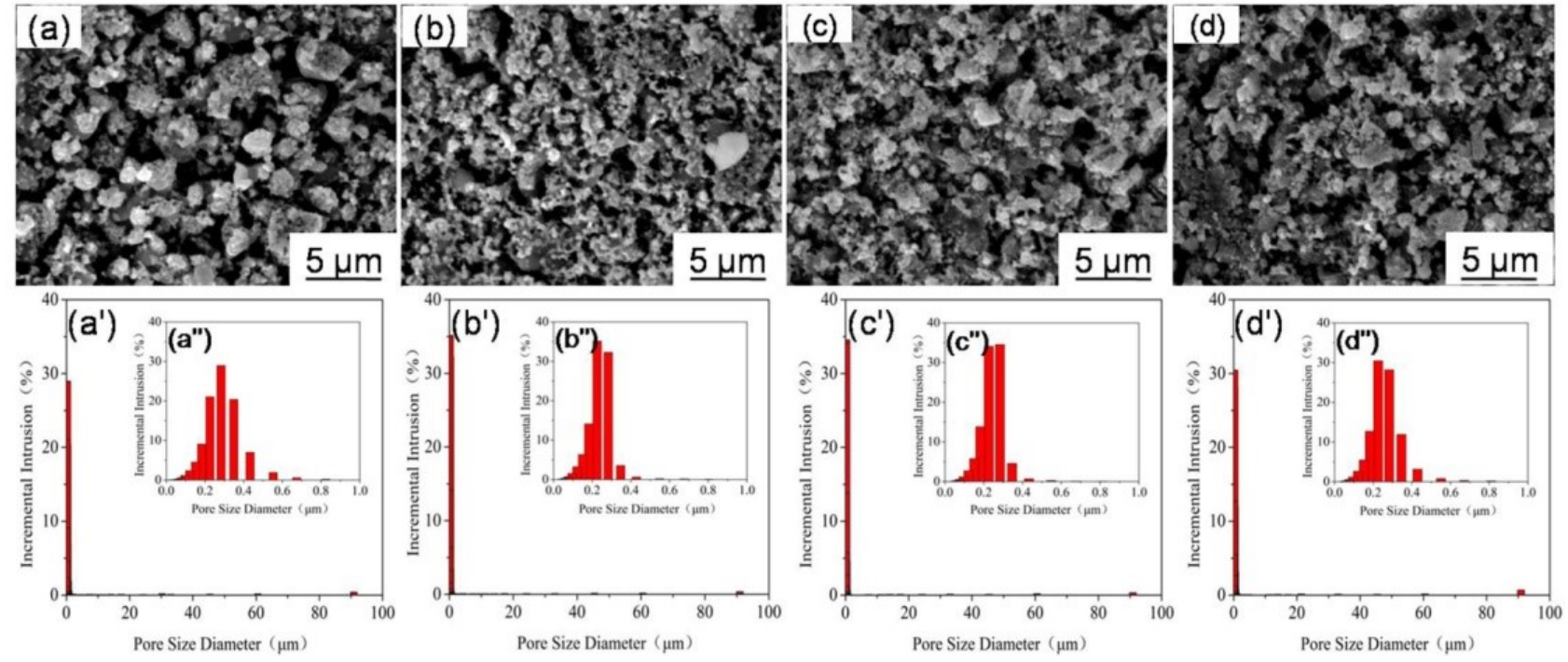

Figure 2: SEM morphologies and pore size distributions of sintered samples with different Mo contents: (a) 12 wt. \%, (b) 14 wt.\%, (c) 16 wt.\%, (d) 18 wt.\%

mately $75 \mu \mathrm{m}$. However, the pore size is mainly less than $1 \mu \mathrm{m}$ because the powders became extremely fine (submicron in size) after ball milling. During high-temperature sintering, the generation of big pores $(>1 \mu \mathrm{m})$ were probably due to stacking between particles with size of $>1 \mu \mathrm{m}$ and the generation of small pores $(>1 \mu \mathrm{m})$ were probably due to the diffusion and reaction between Ti/Mo and Si. It was concluded that the small pores were formed because of the reaction between $\mathrm{Ti} / \mathrm{Mo}$ and $\mathrm{Si}$ and the mutual diffusion between the Ti and Mo particles. An abundance of pores with sizes less than $1 \mu \mathrm{m}$ could influence the properties of porous Ti-Si-Mo intermetallic compounds.

\subsection{Phase Composition}

The phase composition of the samples with different Mo contents is shown in Figure 3. It was concluded that porous Ti-Si-Mo intermetallic compounds fabricated by reactive synthesis consist of $\mathrm{Mo}_{5} \mathrm{Si}_{3}, \mathrm{TiSi}, \mathrm{Ti}_{5} \mathrm{Si}_{4}, \mathrm{Ti}_{5} \mathrm{Si}_{3}$ and $\mathrm{TiO}$. There are TiSi and $\mathrm{Mo}_{5} \mathrm{Si}_{3}$ phases in all the samples. As the Mo content in the powder mixtures increased, the $\mathrm{Ti}_{5} \mathrm{Si}_{4}$ phase was formed. In particular, the $\mathrm{Ti}_{5} \mathrm{Si}_{3}$ phase was detected at Mo content of $16 \mathrm{wt} . \%$. In addition, a small amount of titanium oxide was formed due to the unavoidable presence of oxygen during the ball milling and sintering procedure, and the titanium oxides could have an effect on the oxidation behavior for the sintered porous TiSi-Mo intermetallic compounds [22].

\subsection{Oxidation Behavior}

The microstructure, phase composition and mass gain curve of the oxidized samples are shown in Figure 4. It was found that the weight of each sample remains nearly stable after $20 \mathrm{~h}$ of oxidation. As the Mo content increased, the mass gain gradually decreased from $0.136 \mathrm{~g} \cdot \mathrm{m}^{-2}$ to $0.092 \mathrm{~g} \cdot \mathrm{m}^{-2}$ after $100 \mathrm{~h}$ of oxidation. A continuous oxides scale was formed at the oxide/air interface, and the oxidized sample surface was basically covered with the $\mathrm{TiO}_{2}$ layer. The outward diffusion of Ti controlled the oxidation rate at temperatures beyond $1173 \mathrm{~K}$, and the external $\mathrm{TiO}_{2}$ layer originated from the substrate surface. The samples were not oxidized further after $20 \mathrm{~h}$ due to the external $\mathrm{TiO}_{2}$ layer. Particularly, the oxidized sample surface with an Mo content of 16 wt. $\%$ consisted of a $\mathrm{TiO}_{2}-\mathrm{SiO}_{2}$ duplex layer because the sample with an Mo content of $16 \mathrm{wt} . \%$ was the only sample that did not contain the TiO phase composition in all the sintered samples, as shown in Fig. 2. The inward diffusion of oxygen without the titanium oxides was worse and it resulted in $\mathrm{TiO}_{2}-\mathrm{SiO}_{2}$ duplex layer underneath [23]. The microstructure has a slight effect on the oxidation behavior because there is little difference among the pore characteristics of the sintered samples, such as porosity, pore size, surface area and fractal dimension. The oxidation weight of porous Ti-Si-Mo intermetallic compounds with various Mo content oxidized at 1473 $\mathrm{K}$ decreased with increasing Mo content. It is supposed that $\mathrm{MoO}_{3}$ volatilized during the oxidation process [24]. According to the Ti-Mo binary phase diagram [25], the Ti$8 \mathrm{Si}-18 \mathrm{Mo}$ alloy is composed of $\beta$-Ti at $1473 \mathrm{~K}$. The oxygen 

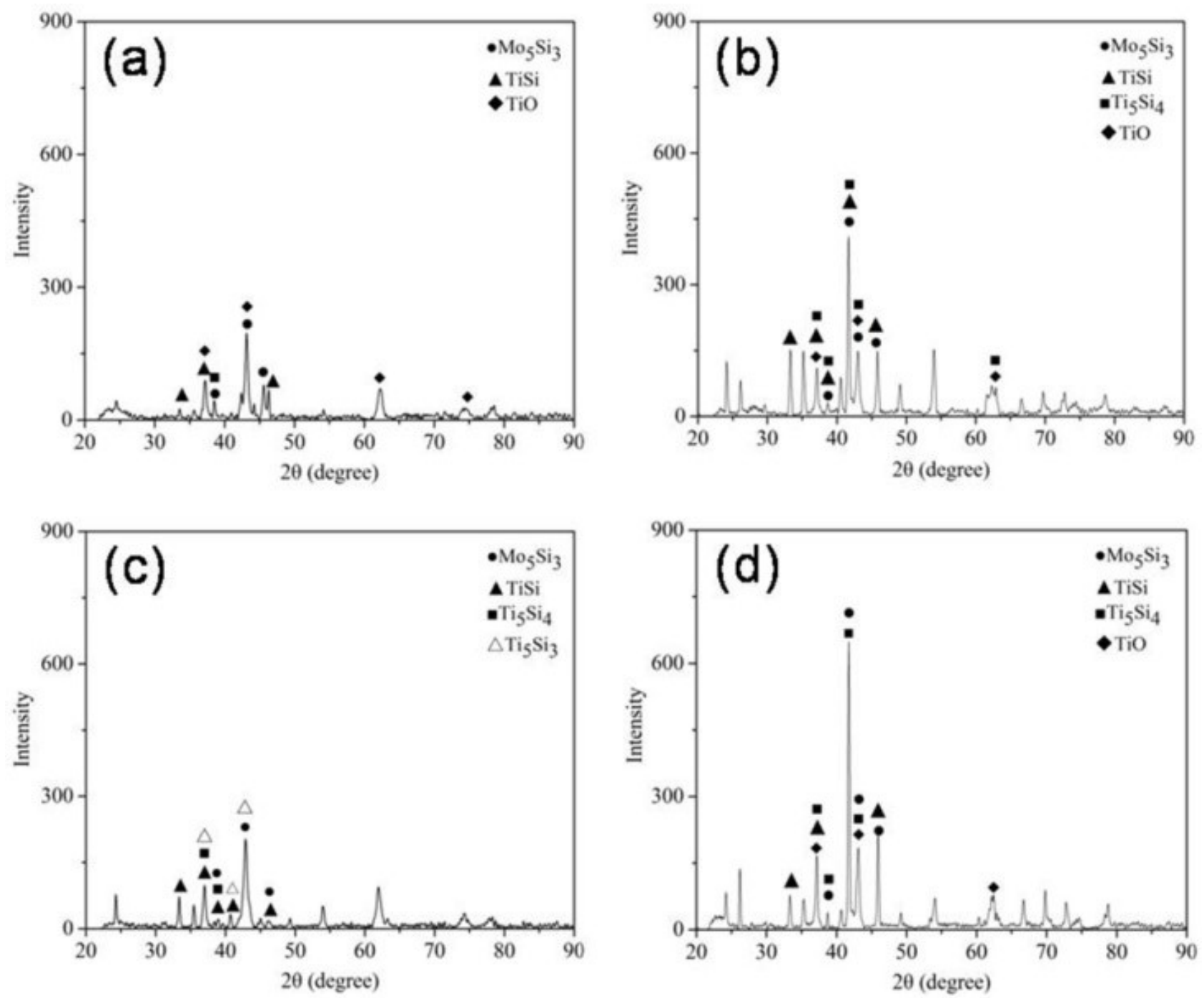

Figure 3: XRD patterns of sintered samples with different Mo contents: (a) 12 wt.\%, (b) 14 wt.\%, (c) 16 wt.\%, (d) 18 wt.\%

solid-solubility of $\beta$-Ti is only $4 \%$ [26]. Hence, the oxidation resistance of sintered samples increases with the increasing of the Mo content. By comparison, the mass gain of porous Ti-8Si-18Mo intermetallic compounds was only approximately $4 \%$ of that of the porous $316 \mathrm{~L}$ stainless steel after $100 \mathrm{~h}$ of oxidation [17]. In summary, porous Ti-Si-Mo intermetallic compounds possess superior oxidation resistance at high-temperature.

\subsection{Fractal Dimension}

The fractal dimension effectively characterizes the complexity and connectivity of pores [27]. The larger the fractal dimension, the more complex the spatial distribution of the material's pores [28]. The fractal dimension of samples with different Mo contents are shown in Table 1 ac- cording to Eq. (1). The fractal dimension decreased from 2.891 to 2.880 and then increased to 2.886 as the Mo content increased. The large fractal dimension proves that the pores of the samples have excellent complexity and connectivity. It is concluded that the fractal dimension is consistent with the porosity for the pore structures with the approximate smallest and largest pore radius. In addition, wider pore size distributions corresponded to larger fractal dimensions when the porosity was constant. In addition, the spatial filling capability is greater as the fractal dimension increases, which could have an effect on the mass and heat transfer performance. It was concluded that the oxidation performance gradually declines as the fractal dimension increased in general because the fractal dimension is higher and because, the area to be oxidized is larger. However, the sample with an Mo content of 18 wt.\% did not conform to this rule because of the evaporation of $\mathrm{MoO}_{3}$ 

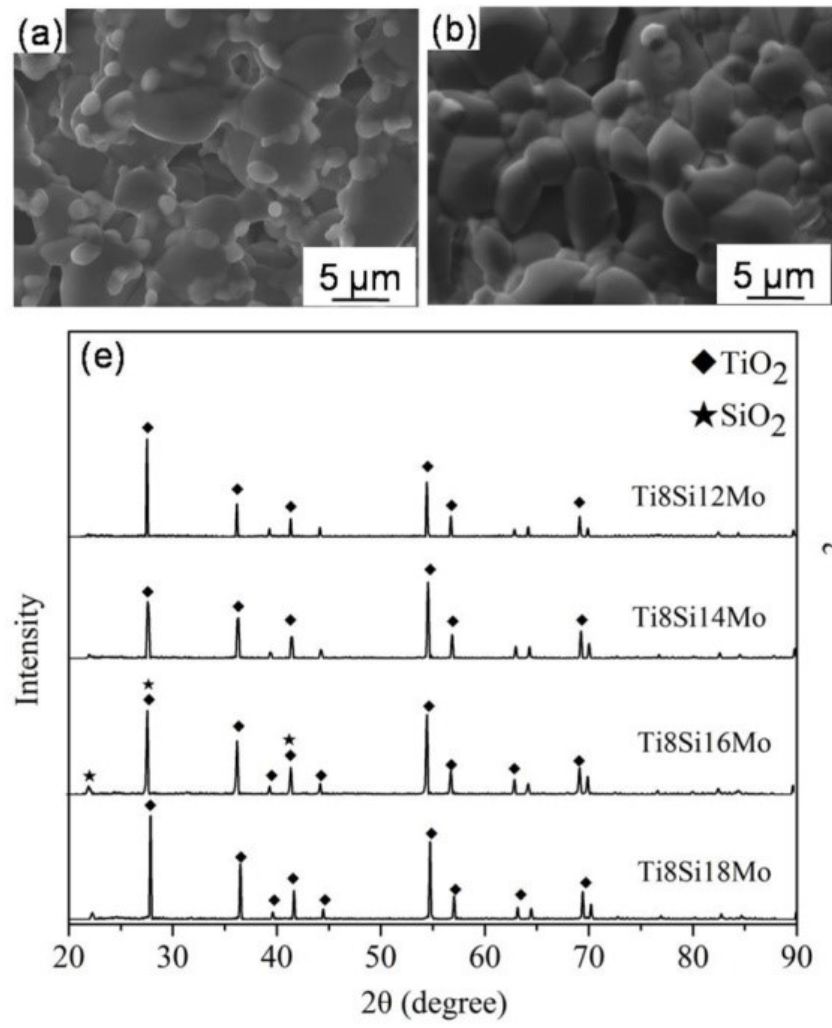
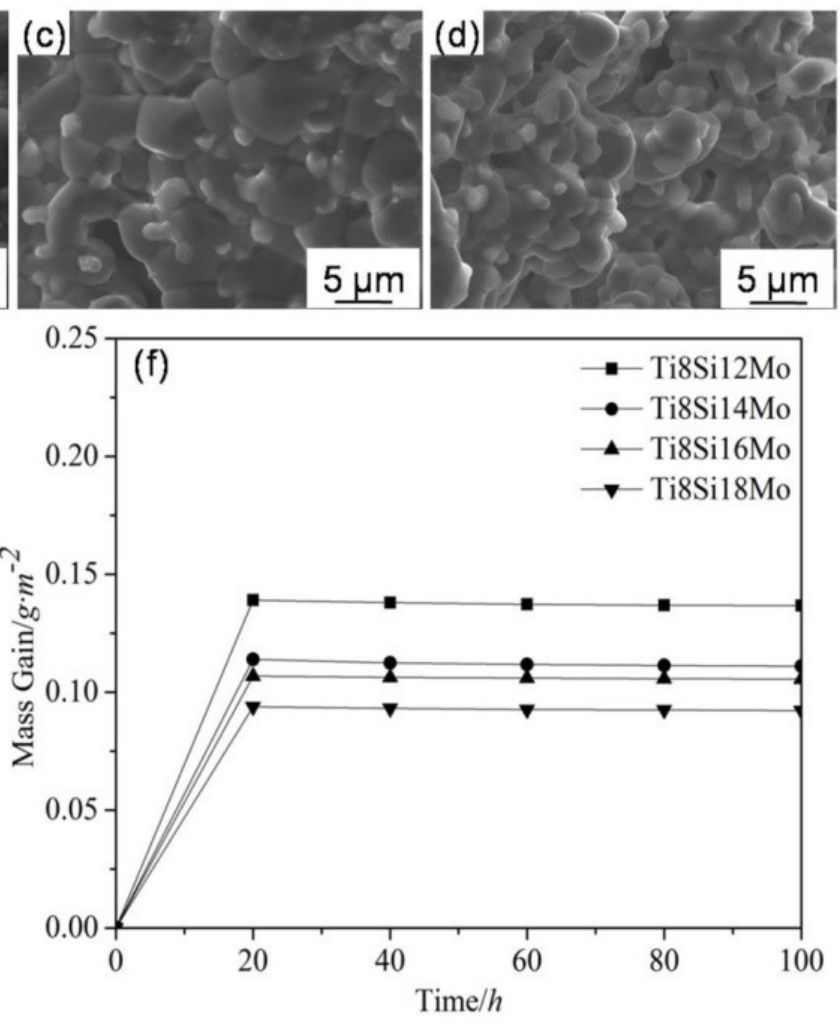

Figure 4: SEM morphologies, XRD patterns and mass gain curves of samples with different Mo contents oxidized at $1473 \mathrm{~K}$ for $100 \mathrm{~h}$ : (a) 12 wt.\%, (b) 14 wt.\%, (c) 16 wt.\%, (d) 18 wt.\%

[13]. Thus, the Mo content has an impact on the oxidation performance in addition to the microstructure.

\section{Conclusions}

In summary, porous Ti-Si-Mo intermetallic compounds were successfully fabricated by the reactive synthesis with $\mathrm{C}_{7} \mathrm{H}_{10} \mathrm{~N}_{2} \mathrm{O}_{2} \mathrm{~S}$ as a foaming agent. The porosity of the samples decreased from $44.18 \%$ to $40.58 \%$ and then increased to $42.54 \%$ as the Mo content increased from 12 wt.\% to18 wt.\%. The pore size distribution was on submicron level, and the average pore diameters were extremely small, ranging from $246.5 \mathrm{~nm}$ to $287.1 \mathrm{~nm}$. The fractal dimension ranged from 2.880 to 2.891 indicating that the pores of samples have excellent complexity and connectivity. The phase compositions of the porous Ti-Si-Mo intermetallic compounds mainly consisted of $\mathrm{TiSi}_{1} \mathrm{Ti}_{5} \mathrm{Si}_{4}, \mathrm{Mo}_{5} \mathrm{Si}_{3}$ and TiO. The porous Ti-Si-Mo intermetallic compounds were not oxidized any more after $20 \mathrm{~h}$ because the surface was mainly covered with a continuous $\mathrm{TiO} 2$ layer. As the Mo content increased from $12 \mathrm{wt} . \%$ to $18 \mathrm{wt} . \%$, the mass gain of porous Ti-Si-Mo intermetallic compounds gradually de- creased from $0.136 \mathrm{~g} \cdot \mathrm{m}^{-2}$ to $0.092 \mathrm{~g} \cdot \mathrm{m}^{-2}$ after oxidation at $1473 \mathrm{~K}$ for $100 \mathrm{~h}$. In addition, the oxidation performance gradually decreased as the fractal dimension increased. Thus, porous Ti-Si-Mo intermetallic compounds possess excellent oxidation at high temperature.

Acknowledgement: The authors acknowledge the financial support of Natural Science Foundation of Jiangsu Province (No. BK20181448), Natural Science Research of Jiangsu Higher Education Institutions of China (No. 17KJB430009) and Senior Talent Foundation of Jiangsu University (No. 15JDG150).

\section{References}

[1] Ru, J. M., B. Kong, T. X. Fan, and D. Zhang. Porous copper with capillary performance and gas permeability prepared by two-step foaming method. International Journal of Precision Engineering and Manufacturing, Vol. 16, No. 7, 2015, pp. 1461-1466.

[2] Lu, G., G. Q. Lu, and Z. M. Xiao. Mechanical properties of porous materials. Journal of Porous Materials, Vol. 6, 1999, pp. 359-368.

[3] Banhart, J. Manufacture, characterisation and application of cellular metals and metal foams. Progress in Materials Science, Vol. 46, No. 6, 2001, pp. 559-632. 
[4] Chen, R., C. A. Wang, Y. Huang, L. Ma, and W. Lin. Ceramics with Special Porous Structures Fabricated by Freeze-Gelcasting: Using tert-Butyl Alcohol as a Template. Journal of the American Ceramic Society, Vol. 90, No. 11, 2007, pp. 3478-3484.

[5] Haraguchi, T., K. Yoshimi, H. Kato, S. Hanad, and A. Inoue. Determination of density and vacancy concentration in rapidly solidified FeAl ribbons. Intermetallics, Vol. 11, No. 7, 2003, pp. 707-711.

[6] Nakajima, H., Fabrication, Properties, and Applications of Porous Metals with Directional Pores. Proceedings of the Japan Academy, Series B, Vol. 86, 2010, pp. 884-899.

[7] Liao, J., T. Chen, B. Huang, G. Shi, and X. Xiong. Influence of the pore structure of carbon fibers on the oxidation resistance of $\mathrm{C} / \mathrm{C}$ composites. Carbon, Vol. 40, 2002, pp. 617-621.

[8] Yang, S. H., W. Y. Kim, and M. S. Kim. Fabrication of unidirectional porous TiAl-Mn intermetallic compounds by reactive sintering using extruded powder mixtures. Intermetallics, Vol. 11, No. 8 , 2003, pp. 849-855.

[9] Zhao, J. C., and J. H. Westbrook. Ultrahigh-Temperature Materials for Jet Engines. MRS Bulletin, Vol. 28, No. 9, 2003, pp. 622-630.

[10] Jarfors, A. E. W., D. L. Butler, and K. L. S. Goi. Microstructure formation of porous sintered $\mathrm{Ti}-\mathrm{Si}-\mathrm{Zr}$ compacts with mechanically alloyed-activated Ti-Si and TiH2 powders. Journal of Alloys and Compounds, Vol. 594, 2014, pp. 202-210.

[11] Suryanarayana, C., and N. Al-Aqeeli. Mechanically alloyed nanocomposites. Progress in Materials Science, Vol. 58, No. 4, 2013, pp. 383-502.

[12] Boyer, R., G. Welsch, and E. W. Collings. Materials properties handbook: Titanium alloys. ASM International, Ohio, 1994, pp. 1035-1048.

[13] Burk, S., B. Gorr, H. J. Christ, D. Schliephake, M. Heilmaier, C. Hochmuth, and U. Glatzel. High-temperature oxidation behaviour of a single-phase (Mo,Ti)5Si3 (Mo-Si-Ti) alloy. Scripta Materialia, Vol. 66, No. 5, 2012, pp. 223-226.

[14] Yang, Y., Y. A. Chang, L. Tan, and Y. Du. Experimental investigation and thermodynamic descriptions of the Mo-Si-Ti system. Materials Science and Engineering A, Vol. 361, No. 1-2, 2003, pp. 281-293.

[15] Ran, H., J. Niu, B. Song, X. H. Wang, P. Z. Feng, J. Z. Wang, Y. $\mathrm{Ge}$, and A. Farid. Microstructure and properties of Ti5Si3-based porous intermetallic compounds fabricated via combustion synthesis. Journal of Alloys and Compounds, Vol. 612, 2014, pp. 337-342.

[16] Gao, H., Y. H. He, P. Shen, J. Zou, N. P. Xu, B. Y. Huang, and C. T. Liu. Porous FeAl intermetallics fabricated by elemental powder reactive synthesis. Intermetallics, Vol. 17, No.12, 2009, pp. 10411046.
[17] He, Y. H., Y. Jiang, N. P. Xu, J. Zou, B. Y. Huang, C. T. Liu, and P. K. Liaw. Fabrication of Ti-Al Micro/ Nanometer-Sized Porous Alloys through the Kirkendall Effect. Advanced Materials, Vol. 19, No. 16, 2007, pp. 2102-2106.

[18] Yin, Y., R. M. Rioux, C. K. Erdonmez, S. Hughes, G. A. Somorjai, and A. P. Alivisatos. Formation of hollow nanocrystals through the nanoscale Kirkendall effect. Science, Vol. 304, No. 5671, 2004, pp. 711-714.

[19] Liu, Y., W. F. Wei, K. C. Zhou, L. F. Chen, and H. P. Tang. Microstructures and mechanical behavior of PM Ti-Mo alloy. Journal of Central South University, Vol. 10, No. 2, 2003, pp. 81-86.

[20] Yu, B. M., and J. H. Li. Some fractal characters of porous media. Fractals, Vol. 9, 2001, pp. 365-372.

[21] Zhu, L. L., Q. F. Zhang, Z. Q. Chen, C. D. Wei, G. M. Cai, L. Jiang, Z. $P$. Jin, and J. C. Zhao. Measurement of interdiffusion and impurity diffusion coefficients in the bcc phase of the Ti-X $(X=C r, H f, M o$, $\mathrm{Nb}, \mathrm{V}, \mathrm{Zr}$ ) binary systems using diffusion multiples. Journal of Materials Science, Vol. 52, No. 6, 2017, pp. 3255-3268.

[22] Diamanti, M. V., S. Codeluppi, A. Cordioli, and M. P. Pedeferri. Effect of thermal oxidation on titanium oxides' characteristics. Journal of Experimental Nanoscience, Vol. 4, No. 4, 2009, pp. 365372.

[23] Melsheimer, S., M. Fietzek, V. Kolarik, A. Rahmel, and M. Schütze. Oxidation of the intermetallics MoSi2 and TiSi2-A comparison. Oxidation of Metals, Vol. 47, No. 1-2, 1997, pp. 139-203.

[24] Yoon, J. K., G. H. Kim, J. H. Han, I. J. Shon, J. M. Doh, and K. T. Hong. Low-temperature cyclic oxidation behavior of MoSi2/Si3N4 nanocomposite coating formed on Mo substrate at $773 \mathrm{~K}$. Surface and Coatings Technology, Vol. 200, No. 7, 2005, pp. 2537-2546.

[25] Yanagihara, K., T. Maruyama, and K. Nagata. High temperature oxidation of Mo-Si-X intermetallics ( $\mathrm{X}=\mathrm{Al}, \mathrm{Ti}, \mathrm{Ta}, \mathrm{Zr}$ and $\mathrm{Y})$. Intermetallics, Vol. 3, No. 3, 1995, pp. 243-251.

[26] Boettinger, W. J., J. H. Perepezko, and P. S. Frankwicz. Application of ternary phase diagrams to the development of MoSi2-based materials. Materials Science and Engineering A, Vol. 155, No. 1-2, 1992, pp. 33-44.

[27] Kuls'kov, S. N., J. Tomaš, and S. P. Buyakova. Fractal dimension of the surface of porous ceramic materials. Technical Physics Letters, Vol. 32, No. 1, 2006, pp. 73-75.

[28] Mandelbrot, B. Fractal Analysis and Synthesis of Fracture Surface Roughness and Related Forms of Complexity and Disorder. International Journal of Fracture, Vol. 138, No. 1-4, 2006, pp. 13-17. 